\title{
LA UTOPÍA AMERICANA DEL OBISPO DE MICHOACÁN DON VASCO DE QUIROGA: ESPIRITUALIDAD Y ECONOMÍA EN LOS PUEBLOS- HOSPITAL
}

\author{
León M. Gómez Rivas \\ (Universidad Europea de Madrid)
}

\section{RESUMEN}

Don Vasco de Quiroga (1488-1565), formado en la Universidad de Salamanca, trabajó como jurista para la Corona española en diversos cometidos, hasta que fue nombrado Oidor de la Audiencia de Nueva España en 1531. Al poco de llegar puso en marcha una sorprendente empresa fundacional en aquel territorio: los PueblosHospital, unas comunidades singulares de indios en torno a un hospital o enfermería. Entre 1531 y 1535 Quiroga promovió dos poblaciones con el nombre de HospitalPueblo de Santa Fe, en las cercanías de México. Los hospitales de Vasco de Quiroga (todavía hoy conocido como Tata Vasco por la población indígena) se consolidaron en la diócesis de Michoacán, de la que fue Obispo hacia 1537. Además de la gestión material de adquirir los terrenos y edificios, don Vasco proyectó la organización económica y social de aquellas comunidades. Con este motivo redactaría una interesante y poco conocida obra: su Información en derecho (1535), que hoy podríamos considerar de carácter utópico y colectivista inspirada en la Utopía de Moro.

PALABRAS CLAVE: México, Pueblo-Hospital, Utopía, Tomás Moro.

\section{THE AMERICAN UTOPIA OF THE BISHOP OF MICHOACÁN DON VASCO DE QUIROGA: SPIRITUALITY AND ECONOMY IN THE HOSPITAL-VILLAGES}

\begin{abstract}
Vasco de Quiroga, born in Castilian lands of Ávila around 1488, left the Iberian Peninsula and sailed towards the New World. He arrived in the new colonial ViceRoyalty of New Spain and Mexico City in 1530. He probably travelled determined to make his favorite reading, Sir Thomas More's Utopia, a dream come true. He not only promoted, protected against the many abuses, and improved the Indian's life conditions from the very beginning, but started building his ideal plans. Between 1531 and 1535 Quiroga founded two utopian communities, both named Hospital-Pueblo
\end{abstract}


de Santa Fe (Hospital-Village of the Holy Faith), in the lands of Mexico City and Michoacán. A few years after, he became Bishop of Michoacán and from this high position continued struggling for the abused and applying firmly his utopian agenda.

KEYWORDS: Mexico, Hospital-Village, Utopia, Thomas More.

\section{INTRODUCCIÓN}

Don Vasco de Quiroga (1488-1565) fue un ilustre personaje de la España Moderna, nacido en Madrigal de las Altas Torres, que proyectó una sorprendente empresa fundacional en México: los Pueblos-Hospital. Compartió con otros protagonistas de aquella época un llamativo espíritu aventurero y empresarial (que hoy llamaríamos "emprendedor"): la puesta en marcha de unos poblados singulares en torno a un hospital o enfermería, en los que vivían agrupaciones familiares dedicadas al cultivo de pequeñas plantaciones cercanas o a la artesanía.

Los Hospitales de Vasco de Quiroga (todavía hoy conocido como Tata Vasco por la población indígena) comenzaron en la diócesis de Michoacán, de la que fue Obispo, hacia 1537. Además de la gestión material de adquirir los terrenos, don Vasco proyectó la construcción de los edificios junto a la organización económica y social de aquellas comunidades. Con este motivo redactaría sus Ordenanzas para el gobierno de los hospitales y una interesante y poco conocida obra: Información en derecho (1535), que hoy podríamos considerar de inspiración utópica y colectivista. No en vano, por otra parte, se le ha atribuido a Vasco de Quiroga la traducción al castellano de la Utopía de Moro (sobre esto volveremos más adelante).

Dicho todo lo cual, añadimos: ¿por qué estudiar a don Vasco? La pregunta es pertinente ya que se trata de un autor bien conocido especialmente en México, menos estudiado en España, y sobre el que existe una abundantísima información documental. Aunque Vasco de Quiroga gozó en vida de fama de santidad, sin embargo se escribió poco en el siglo XVI sobre su persona y actividad. Quien primero dejó constancia sobre don Vasco, sin pretender hacer una biografía formal, fue Cristóbal Cabrera (1515-1589), clérigo burgalés ordenado sacerdote por el ya Obispo Quiroga, a quien acompañó como secretario en los primeros siete años de su ministerio 
episcopal en Michoacán ${ }^{1}$. Un siglo después, Francisco Arnaldo de Yssasi incluyó un relato de su vida en la Demarcación y descripción del obispado de Michoacán ${ }^{2}$. En el siglo XVIII se publicó un trabajo ya específico sobre Vasco de Quiroga: los Fragmentos de la vida y virtudes de ilustrísimo y reverendísimo señor doctor don Vasco de Quiroga $(1766)^{3}$. El siglo XIX es de silencio pues hay muy pocas referencias hacia su persona y obra; hasta llegar al siglo XX, cuando aparecerán una cantidad notable de estudios serios y profundos sobre Vasco de Quiroga. Muchos de ellos, sin embargo, repiten la misma información. En los últimos años esta documentación sigue aumentando, gracias a que se ha podido contar con los expedientes de los diversos pleitos judiciales en los que estuvo involucrado don Vasco, junto a los papeles que se han aportado al Proceso de su Causa de Canonización.

Una buena muestra de lo mucho que se ha escrito sobre Vasco de Quiroga puede ser el trabajo del profesor Arce, una Guía Bibliográfica que detalla por extenso casi todo lo que se ha publicado a la fecha sobre nuestro Prelado. Sobresalen las aportaciones de: Nicolás León (1859-1929); Silvio Zavala (1909-2014); Rafael Aguayo Spencer (1914-1982); Alberto Carrillo Cázares (1923); Francisco Martín Hernández (1927); Benedict Warren (1930); Francisco Miranda Godínez (1937); Armando Escobar Olmedo (1944), el propio Pablo Arce Gargollo (1954) o Juan Robles Diosdado (1965).

Y así llegaríamos hasta el siglo XXI, en el que se editaba hace poco la última referencia que conozco sobre don Vasco: lo que parece fue una Tesis Doctoral de Juan Robles Diosdado: V asco de Quiroga. Laico misionero (2010). De este libro he obtenido la información referida, así como un estado de la cuestión sobre don Vasco que completa el de Arce Gargollo. Robles Diosdado nos presenta lo que él titula «Una multitud de aproximaciones» bibliográficas (p. 25) a partir del siglo XX, que se verían impulsadas por la coincidencia de los centenarios de la muerte de Quiroga (1965) y del Descubrimiento de América (1992). En total, nos ofrece una lista de más de cincuenta autores (algunos de ellos con varias obras sobre don Vasco), además de casi diez tesis doctorales inéditas ${ }^{5}$. Entre la bibliografía citada quiero destacar al gran historiador mexicano don Silvio Zavala, fallecido recientemente.

Con todo este abundante repertorio bibliográfico, podría pensarse que apenas quede espacio para aportaciones originales. Lo que en cierta medida es correcto, de

\footnotetext{
${ }^{1}$ Cristóbal Cabrera, De Sollicitanda Infidelium Conversione (Biblioteca Vaticana, Colección Barberini, Códice Misceláneo Vat. Lat. 5026).

${ }^{2}$ Francisco Arnaldo de Yssasi, Demarcación y Descripción de Michoacán (1649), en Bibliotheca Americana (1982), vol. I, n. 1, pp. 61-204. El manuscrito se localiza en la "Ayer Collection of Americana”, MS 1106.

${ }^{3}$ Juan Joseph Moreno, Fragmentos de la Vida y Virtudes del V. Ilmo. y Rmo. Sr. Dr. D. Vasco de Quiroga (México, Imprenta del Real y más antiguo Colegio de San Ildefonso, 1776).

${ }^{4}$ Pablo Arce Gargollo, "Guía Bibliográfica”, en V asco de Quiroga, jurista con mentalidad secular (México: Porrúa, 2007).

${ }^{5}$ Juan Robles Diosdado, V asco de Quiroga. Laico misionero (Morelia: UVAQ, 2010).
} 
forma que nuestra Comunicación simplemente va a intentar presentarles un recuerdo de don $V_{\text {asco }}{ }^{6}$, tal vez con la novedad de relacionarlo en su tarea fundacional y espíritu emprendedor con santa Teresa de Jesús (hemos celebrado hace poco su Quinto Centenario); aludiendo también a esa posible -y más estudiada- inspiración utópica y moreana. Pues bien, en las páginas que siguen voy a desarrollar estas ideas con dos herramientas de análisis teórico también recientes, que veremos en el siguiente apartado: el libro Trabajo, dinero y negocios, del profesor José A. Alvarez Vázquez, y sendos artículos del profesor Manuel Santos ${ }^{7}$.

\section{UNA TEORÍA DEL EMPRESARIO EN LA ESPAÑA MODERNA}

Al iniciarse este siglo XXI se publicaba precisamente ese estudio económico sobre las Fundaciones de Teresa de Ávila, que luego he visto citado en varios trabajos similares. Me ha parecido muy interesante su Introducción, en la que el autor plantea cómo no deberían ser incompatibles la espiritualidad y los negocios, la economía y el cristianismo... Ciertamente (y dejando aparte algunos movimientos que podríamos llamar de ultra-pobreza, por lo demás condenados por la Iglesia), no parecería ser algo ajeno a la vida cristiana el ocuparse de las necesidades materiales.

Como digo, el resto del libro es un completo análisis de la "gestión económica" de santa Teresa (que no veremos ahora) en torno a tres ideas:

- su actuación personal directa, de la que conservamos abundantes documentos ya que -como se quejaba con frecuencia- tuvo que dedicarle a ello mucho tiempo, y se esforzó en aprender ("no queremos ir por caminos no andados"; p. 16).

- la formulación de lo que llamaríamos "un esquema económico teresiano"

- la constatación de que el estudio de esa faceta de la Santa nos permitirá conocer más cabalmente a Teresa de Jesús.

De manera que recojo esta aproximación teresiana como posible ejemplo para acercarnos igualmente a las empresas de Vasco de Quiroga. Considero que ambos parten de un similar enfoque cristiano sobre la pobreza y la riqueza: los medios materiales fueron imprescindibles para llevar a cabo su obra fundacional. Así, aunque la Santa «tenía aborrecidos dineros y negocios, quiere el Señor que no trate en otra cosa», llegando con el tiempo -señala el profesor Álvarez- a tener un buen conocimiento de

\footnotetext{
${ }^{6}$ He replicado a propósito el título de uno de los libros de Silvio Zavala, Recuerdo de V asco de Quiroga (México: Porrúa, 1965).

${ }^{7}$ José Antonio Álvarez Vázquez, Trabajo, dinero y negocios (Madrid: Trotta, 2000); Manuel Santos Redondo. "Espíritu de empresa: mentalidades y teorías del empresario", en Estudios de historia del pensamiento económico: homenaje al profesor Francisco Bustelo (Madrid: Editorial Complutense, 2003): 531-540; Manuel Santos Redondo, "La economía y la empresa en las novelas de Cervantes", CLM Economía 5 (2004): 161-188.
} 
la sociedad y la economía de su época ${ }^{8}$. La clave estaría, al igual que con el obispo Quiroga, en mantener la virtud del desprendimiento cristiano, una "pobreza interior" muy habitual en este tipo de "empresarios ascéticos" como podríamos definirles. Los dos compartieron esa perspectiva evangélica de «no poner tu confianza en el dinero», pero gestionándolo al tiempo con habilidad y perspicacia. Álvarez Vázquez abunda en esta idea, señalando cómo Teresa de Jesús, a base de tomar decisiones, llegó a conseguir un eficaz acierto en ellas. Lo que habla de un carácter innovador desde el punto de vista económico e institucional; y cita un artículo suyo en el que estudia las «condiciones generales» que posibilitaron el surgimiento de individuos capaces como santa Teresa ${ }^{9}$ (nosotros añadimos a don Vasco). Aquella pudo presumir de «no ser ignorante de las leyes del mundo», transmitiendo con satisfacción esta sabiduría a sus prioras y a los miembros de la orden masculina: lo que resume nuestro autor en principios como la libertad, el respeto a las personas y el cumplimiento de los contratos $^{10}$.

Ideas que completo ahora con la interesante línea argumental del profesor Santos Redondo, iniciada en un artículo de $2003^{11}$. Manuel Santos, autor de una tesis doctoral en la que explica la teoría del "empresario innovador" de Schumpeter", aplicaría aquí este modelo al análisis de los "éxitos" en la gestión del Imperio español (cita para ello un famoso libro de McLelland) ${ }^{13}$ : la historia y la literatura del Cid, el Quijote o el Buscón de Quevedo nos hablan de una «sociedad ambiciosa», repleta de grandes personajes con «actitudes empresariales».

Poco después desarrollará por extenso esta idea sobre la complementariedad del idealismo quijotesco y un espíritu empresarial de innovación schumpeteriana ${ }^{14}$. Ese "impulso creativo" lo vemos aplicado ahora a las empresas espirituales de Teresa de Jesús o Ignacio de Loyola, sin perder de vista la España de Cervantes (se recordaba entonces el Centenario del Quijote). Y remite aquí al libro de José Antonio Álvarez que he señalado, con su análisis de los catorce monasterios fundados por santa Teresa (ique inició a los 47 años!), en el que habla de coherencia, información y decisión, proponiendo a la Santa como un caso de «liderazgo con éxito».

Sin embargo, no es objeto de nuestro trabajo continuar en esta línea de un estudio teórico sobre los fundamentos del espíritu empresarial en aquellos personajes de la España moderna, sino ofrecer una visión más descriptiva de los Pueblos-Hospital

\footnotetext{
8 Álvarez Vázquez, Trabajo, dinero y negocios: 17.

9 José Antonio Álvarez Vázquez. "Financiación de las fundaciones teresianas", en Actas del I Congreso Internacional Teresiano (Salamanca-Madrid: Universidad Pontificia-Ministerio de Cultura, 1983), 249-285.

10 Álvarez Vázquez, Trabajo, dinero y negocios: 18.

11 Santos Redondo. "Espíritu de empresa".

${ }^{12}$ Manuel Santos Redondo, Los economistas y la empresa. Empresa y empresario en la historia del pensamiento económico (Madrid: Alianza Editorial, 1997).

${ }^{13}$ David C. McLelland, The Achieving Society (Princeton, NJ: D. Van Nostrand, 1961).

${ }^{14}$ Santos Redondo, "La economía y la empresa en las novelas de Cervantes".
} 
de don Vasco, desde una perspectiva de la Historia del Pensamiento Económico, relacionándolos con la famosísima Utopía de Tomás Moro, que ya he adelantado (y lo veremos enseguida) tiene bastante relación con Quiroga.

\section{VASCO DE QUIROGA: UNA BIOGRAFÍA APRESURADA (1488-1565)}

Regresando a nuestro autor repasaremos brevemente su trayectoria vital: se trata de un paisano abulense de Teresa de Jesús, ya que don Vasco nació en Madrigal de las Altas Torres (por cierto, como otros ilustres personajes entre los que destaco a la reina Isabel la Católica o don Alonso Fernández, "el Tostado", que sería obispo de Ávila). Su familia era de origen gallego, los Vázquez de Quiroga, de la que también nació el futuro cardenal arzobispo de Toledo, Gaspar de Quiroga.

Parece que don Vasco estudió en Valladolid y en Salamanca, donde coincidiría con otro amigo de su infancia abulense: don Juan Tavera, después también arzobispo de Toledo. Licenciado en Cánones, trabajó para la administración real como Juez de Residencia en Orán y en Murcia, actuando como representante de la Corona (estamos en los tiempos de Carlos V) en ciertas negociaciones diplomáticas con los reinos moros del norte de África. Viajo con la Corte de Burgos a Madrid en 1528 y sabemos que fue en 1529, estando en Murcia, cuando le llegó una invitación de la Reina para ejercer el puesto de Oidor en la Segunda Audiencia de la recién conquistada Nueva España.

Este periodo americano de su vida es el mejor conocido, sobre todo a partir de aquella primera biografía suya casi contemporánea, y gracias también a la documentación civil y eclesiástica que se conserva de los tiempos del Virreinato. Aunque precisamente sobre ese nombramiento para la Audiencia de México existe alguna pequeña contradicción entre lo que narra el clérigo Cristóbal Cabrera (indicando haberlo escuchado de boca del propio don Vasco) y la documentación original que conservamos. Lo explica muy bien Robles Diosdado citando el texto de Cabrera:

Encontrándose en la Corte del Emperador, le sobrevino una terrible angustia por no saber qué hacer ni qué elegir, en vista de que el Emperador le ofrecía por medio del Canciller y Arzobispo Primado de España, don Juan Tavera de mucho valimiento ante el monarca y muy adicto a Quiroga, una magistratura o una gobernación en España, o un puesto en el Tribunal del Santo Oficio de la Inquisición, o bien una magistratura en el gobierno de las Indias para que en él ayudara a la conversión de los naturales, sirviendo así mejor a Dios y al Rey ${ }^{15}$.

En estas circunstancias, explicaba Cabrera, tuvo lugar una especie de moción divina sobre Quiroga al escuchar en un monasterio el Salmo 4 («Ofreced sacrificios de

\footnotetext{
${ }^{15}$ Robles Diosdado, Vasco de Quiroga: 256.
} 
justicia y confiad en Dios»), que le llevaría a decidirse por la empresa americana, como expresión de una patente vocación misionera (precisamente sobre este aspecto de la misión evangelizadora de los laicos españoles en el siglo XVI escribe todo un capítulo el historiador mexicano Juan Robles Diosdado). Pues bien, como él mismo indica, «seguramente la narración de los hechos no corresponde a lo que históricamente tuvo lugar» ${ }^{16}$ y nos remite al trabajo de Martín Hernández ${ }^{17}$.

Aunque parece que don Vasco sí pudo haberse entrevistado con Tavera y el Emperador antes del verano de 1529, para tratar de su carrera al servicio de la Corona, el nombramiento como Oidor de Nueva España no tiene lugar hasta diciembre de ese mismo año, por carta de la Reina Isabel (13 de diciembre de 1529) que se conserva en el Archivo General de Indias:

La Reyna. Licenciado Quiroga: porque para entender en algunas cosas de nuestro servicio es menester vuestra persona, yo vos mando que luego que ésta recibáis os partáis y vengáis a mí, que brevemente seréis despachado ${ }^{18}$.

La interpretación de Francisco Martín, como decimos, es que si bien don Vasco pudo entrevistarse con el Emperador en 1529, no parece que tuviera lugar una conversación relatada por Cabrera en la que nuestro Obispo, movido por las palabras del Salmo, pactaría con Carlos $V$ el destino a Nueva España... Sino que el nombramiento fue posterior, estando el Emperador ausente de nuestra península. Pero el dato del Salmo sí que es relevante, porque precisamente lo elegirá Vasco de Quiroga como lema episcopal: Sacrificate sacrificium iustitae, et sperate in Domino ${ }^{19}$.

\section{VASCO DE QUIROGA, OIDOR EN LA SEGUNDA AUDIENCIA DE MÉXICO}

A partir de este momento es cuando contamos con la información más ajustada sobre la actividad de don Vasco en Nueva España. El asunto de la Audiencia es bastante interesante -aunque no lo vamos a referir con detalle- porque se trató de la revocación del primer Presidente, Nuño de Guzmán, quien fue procesado por Sebastián Ramírez de Fuenleal, Obispo de Santo Domingo en La Española, y nombrado por la Reina sustituto en la referida Presidencia junto con un nuevo equipo de Oidores, entre los que estaba Quiroga.

Fuenleal representaría un cambio decisivo en la gestión del Nuevo Mundo, buscando el establecimiento de un equilibrio entre "las repúblicas de castellanos y de

\footnotetext{
${ }^{16}$ Ibídem.

${ }^{17}$ Francisco Martín Hernández, Don V asco de Quiroga (protector de los indios) (Salamanca: Universidad Pontificia- Caja de Salamanca y Soria, 1993): 50-53.

18 AGI, México, leg. 1088, fol. 94.

19 Martín Hernández, Don V asco de Quiroga: 54.
} 
indígenas", que le llevó a solicitar nuevos obispados para México (uno de ellos lo ocuparía don Vasco), reclamando a los pastores "que sepan andar a pie... y alimentarse con los indígenas"; es decir, un conocimiento profundo de la compleja realidad indígena, en la que "había señores tan legítimos como los españoles". Vasco de Quiroga será un buen ejemplo de esta nueva actitud en el gobierno y la evangelización americana.

Fuenleal y Quiroga, lo mismo que el obispo Marroquín de Guatemala (o años más tarde, el virrey del Perú don Francisco de Toledo) coincidirían en un proyecto de organizar a los indios en nuevos poblados, donde pudieran sustentarse con su trabajo, y se les atendiera espiritualmente por alguna comunidad de frailes. Sin embargo, don Vasco añadirá a esta idea un plan de "Hospitales" absolutamente personal y que explicaremos enseguida.

Pero continuemos antes con el Oidor de Nueva España don Vasco de Quiroga. Junto con sus compañeros Ceynos, Maldonado y Salmerón, fueron recibidos con entusiasmo (estamos en diciembre de 1530) por el pueblo mexicano, escandalizado y oprimido por los abusos del primer presidente Nuño de Guzmán: sometiendo a los indios a esclavitud, haciendo callar a los frailes que protestaban por ello, o repartiendo y quitando a su antojo las encomiendas a los conquistadores. Ya hemos visto cómo Ramírez de Fuenleal, que llegaría más tarde (en septiembre de 1531), sometió a su antecesor a un Juicio de Residencia; mientras que los oidores se aplicaron a pacificar los ánimos, enmendando errores; a desterrar la esclavitud de los indios, procurando su conversión; a fundar colegios, abrir nuevos caminos o establecer la imprenta en México (que sería la primera del continente americano).

\section{UN LAICO MISIONERO. LOS PUEBLOS-HOSPITALES}

Hemos señalado que la más reciente publicación sobre don Vasco se titula precisamente: Vasco de Quiroga. Laico misionero. Su autor dedica varios capítulos a describir la inspiración cristiana y misionera de Quiroga (antes de ser clérigo), tanto en su decisión de viajar a México, como en su posterior empresa fundacional de los Pueblos-Hospitales. Para ello, va a situarnos en la sociedad española del siglo XVI, de profundas convicciones religiosas no solo entre los clérigos o monjes: Robles Diosdado explica que don Vasco, lo mismo que por ejemplo Cristóbal Colón o tantos otros conquistadores y gobernantes del Nuevo Mundo, estuvieron convencidos de protagonizar una nueva etapa en la historia de la Iglesia, que culminaría precisamente con la conversión de aquellos Cielos nuevos y nuevas tierras de los que habla la Escritura (Apocalipsis 21, 1).

Vasco de Quiroga, laico, miembro del aparato judicial de la Monarquía española, también va a sentirse comprometido en la tarea de la evangelización de América. Y su aportación específica serán los Pueblos Hospitales que venimos 
indicando. Este proyecto aparece bastante bien delimitado en una carta suya al Consejo de Indias, muy poco tiempo después de haber llegado a la Audiencia de Nueva España. Por su interés, la transcribimos por extenso:

También escribimos sobre ciertas poblaciones nuevas de indios que conviene mucho hacerse, que estén apartadas de las viejas en baldíos que no aprovechan a las viejas y de que, trabajando, se podrán muy bien sustentar estas nuevas poblaciones que digo, rompiendo y cultivando los dichos baldíos, y ésta es sin duda una gran cosa y muy útil y necesaria, porque de ello se siguen los provechos siguientes: uno, que lo baldío y estéril aprovechará y dará su fruto y se cultivará y no estará perdido. Lo otro, que estas nuevas poblaciones se han de hacer de los indios que desde muchachos se crían y doctrinan con gran diligencia y trabajo de los frailes que están en estas partes... pueblos muy concertados y ordenados, porque, como viven tan derramados sin orden ni concierto de pueblos ${ }^{20}$.

Ya en 1532 funcionaban dos "hospitales" (uno en la ciudad de México y el otro a orillas del lago de Pátzcuaro, en lo que hoy es el pueblo de Santa Fe), aunque este nombre induce a confusión: en realidad se trataba del poblado en torno a un edificio común, que podía hacer las veces de hospital o enfermería. Las familias indígenas vivían en las casas de alrededor, cada una con un pequeño terreno para huerta. Don Vasco irá redactando con el tiempo unas Ordenanzas que establecieron por ejemplo un sistema de elección para los cargos de gobierno, y detallaron hasta los mecanismos de aprovisionamiento o de trabajo femenino (también ocupándose de los vestidos de los habitantes, todos iguales).

\section{DON VASCO, PRESBÍTERO Y OBISPO DE MICHOACÁN.}

Dada la enormidad del territorio mexicano, ya en las primeras cartas a la Corona del flamante Presidente y Oidores se proponía la creación de nuevos obispados, al tiempo que aprovechaban para describir el territorio y sus gentes. A lo que respondería el Rey en febrero de 1534, erigiendo las diócesis de Michoacán, Oaxaca y Chiapas. Don Vasco será propuesto como Obispo de la primera en 1535, después de la renuncia del franciscano fray Luis de Fuensalida, siendo confirmado por Bula de Paulo III en 1536. Para ello, hubo de ordenarse primero sacerdote, recibiendo la consagración episcopal en 1538 de manos del arzobispo Juan de Zumárraga.

Además de una intensa labor pastoral, que comenzaría levantando físicamente la nueva catedral y edificios episcopales, don Vasco no vivió ajeno a los acontecimientos peninsulares y aún europeos. Quiso viajar a España para asistir al

${ }^{20}$ Carta del licenciado Quiroga, oidor de la Audiencia de Nueva España al Consejo de Indias, 14 de agosto de 1531. En Vasco de Quiroga: La utopia en América, ed. Paz Serrano Gassent (Madrid, Dastin: 2002): 62-63. 
Concilio de Trento (1542), pero una avería en su nave lo impidió. Años más tarde, lo encontramos en la Corte desde 1548 a 1554 resolviendo asuntos relacionados con su fundación de los Pueblos-Hospital, la citada catedral o el seminario y colegio de San Nicolás. También aprovechó esa estancia para editar en Sevilla un Libro de la doctrina cristiana (1554), o establecer contactos con algunos miembros de la recién fundada Compañía de Jesús, solicitando el envío de jesuitas a su diócesis.

Ya de regreso en México, asistió al Concilio Provincial de 1555, continuando con tesón su labor pastoral hasta encontrar la muerte diez años más tarde, al parecer, durante una visita al territorio de Uruapan. Según reza la inscripción de su tumba en la catedral de Pátzcuaro tendría 95 años, aunque seguramente fue un error al haberse atribuido su nacimiento en 1470, siendo más probable en la fecha de 1488 que hemos recogido aquí.

\section{QUIROGA Y TOMÁS MORO: ECONOMÍA O UTOPÍA}

La primera edición de la Utopía de Tomás Moro se había publicado en Lovaina a finales de 1516; la segunda se hizo en París al año siguiente, y la tercera en Basilea en $1518^{21}$. A don Vasco le llegó un ejemplar de la tercera edición, que anotó de su puño y letra, y que hoy conservamos junto a los otros 625 libros que legó a su colegio de San Nicolás en Pátzcuaro. No fue el único español del Nuevo Mundo interesado en la obra de Moro, escrita precisamente al calor de las noticias del Descubrimiento de América: sabemos que el obispo de México, fray Juan de Zumárraga, poseyó un ejemplar de la edición de 1518; lo mismo que el hijo de Cristóbal Colón, Hernando.

Para don Vasco, Tomás Moro fue un «grand griego y gran experto y de mucha autoridad» que escribió con «elegante estilo» su Utopía, «a lo menos en el latín, donde yo a la letra lo saqué y traduje para este fin y efecto». Se ha discutido mucho sobre esa hipotética traducción al castellano de la obra de Moro, algo sobre lo que no podemos detenernos ahora; lo que sí sabemos es la admiración de Quiroga por el canciller inglés, como escribe en su Información en Derecho (de la que hemos sacado estas citas): "porque me parece que fue como por revelación del Espíritu Santo para la orden que convendría y sería necesario que se diese en esta Nueva España y Nuevo Mundo» ${ }^{22}$. Orden que don Vasco parece querrá seguir al pie de la letra cuando se proponga la fundación de sus Pueblos-Hospital.

Llegados a este punto, debemos advertir que no es posible presentar una valoración cabal sobre la Información en Derecho en las pocas páginas que permiten las comunicaciones al presente Congreso. Pero sí deseo ofrecer al lector interesado varias pistas para un mejor conocimiento de la materia, a partir de dos autores que han

\footnotetext{
${ }^{21}$ Martín Hernández, Don Vasco de Quiroga: 35.

${ }^{22}$ Edición de Paz Serrano, en Quiroga, La utopía en américa: 218 y 234.
} 
estudiado con enorme detenimiento a Vasco de Quiroga y su obra. Me refería al principio al ilustre historiador mexicano don Silvio Zavala: ya desde 1937, precisamente con un artículo sobre "La utopía de Tomás Moro en la Nueva España", comenzó una larga serie de publicaciones en torno a don $\mathrm{Vasco}^{23}$.

Más recientemente debemos señalar las investigaciones de la profesora Paz Serrano Gassent, a partir de una Tesis Doctoral sobre don Vasco, defendida en la UNED en 1994 y origen de su publicación; completada poco después por una nueva edición de la Información en derecho y otros escritos de Quiroga ${ }^{24}$. De su lectura provienen las ideas que sugiero en el siguiente epígrafe de mi trabajo; particularmente utilizo su capítulo sobre «El sistema económico».

Pero antes, cerraré esta somera presentación bibliográfica con dos consideraciones respecto a -en este caso- la ausencia de referencias a Vasco de Quiroga en otra importante literatura americanista. Señalo primero el trasfondo, y luego cito autores: se trata de, una vez más, el complejo y sorprendentemente moderno debate sobre la Justas Causas para el descubrimiento, ocupación y conquista de América, que enfrascó a políticos e intelectuales españoles durante buena parte del siglo XVI. Vasco de Quiroga no se sustrajo a esa polémica, ya que el objeto de su Información en derecho fue precisamente este asunto ${ }^{25}$; pero lo curioso es que apenas se le cita en la historiografía correspondiente. Por ejemplo, no he encontrado ninguna referencia a don Vasco en la moderna edición del De Iusto Bello contra Indos redactado en ese mismo Virreinato de Nueva España por Alonso de Veracruz hacia $1555^{26}$; escrito que anteriormente había trabajado con detalle Prometeo Cerezo en su Alonso de Veracruzy el derecho de Gentes, quien tampoco se refiere a Vasco de Quiroga ${ }^{27}$.

Algo similar podemos decir alrededor de un mucho más famoso protagonista de la historia mexicana virreinal, el padre Bartolomé de Las Casas, precisamente obispo en ese Nuevo Mundo como don Vasco. Pues bien, sin realizar una pesquisa exhaustiva, puedo constatar que tampoco se habla de Vasco de Quiroga en los trabajos de ese gran estudioso de Las Casas como fue Lewis Hanke, en dos de sus más famosas obras ${ }^{28}$. Y

\footnotetext{
${ }^{23}$ Silvio Zavala. "La utopía de Tomás Moro en la Nueva España y otros estudios", en Biblioteca histórica mexicana de obras inéditas, vol. 4 (México, Porrúa: 1937); editado con otros 22 artículos más en Zavala, Recuerdo. Posteriormente destacan: Silvio Zavala, Filosofía de la conquista (México: Fondo de Cultura Económica, 1984); Silvio Zavala, Las instituciones jurídicas en la conquista de América (México, Porrúa, 1971); y Silvio Zavala, Temas hispanoamericanos en su Quinto Centenario (México: Porrúa, 1986).

${ }^{24}$ Paz Serrano Gassent, V asco de Quiroga. Utopia y derecho en la conquista de América (Madrid: Fondo de Cultura Económica, 2001). Quiroga, La utopía en América.

${ }^{25}$ Junto con otro escrito suyo, aparentemente desaparecido: De debellandis indis, que en estos últimos años se halla en medio de una interesante pesquisa sobre su posible localización.

${ }^{26}$ Alonso de Veracruz, De Iusto Bello contra Indos (Madrid: CSIC, 1997).

${ }^{27}$ Prometeo Cerezo, Alonso de Veracruz y el derecho de Gentes (México: Porrúa, 1985).

${ }^{28}$ Lewis Hanke, La lucha por la justicia en la conquista de América (Madrid: Itsmo, [1949] 1988); Lewis Hanke, Estudios sobre fray Bartolomé de Las Casas y sobre la lucha por la justicia en la conquista española de América (Caracas: Universidad Central de Venezuela, 1968).
} 
así podríamos seguir adelante: a pesar de todo lo que vengo escribiendo, sin duda que nuestro Tata Vasco es uno de esos personajes que a la vez han sido más abundantemente citados así como han pasado más desapercibidos en la historiografía americanista.

\section{INFLUENCIAS Y ECO DEL PENSAMIENTO DE MORO EN LOS PUEBLOS-HOSPITAL}

Voy a terminar fijándome en tres aspectos que me parece pueden resultar de interés para una reflexión en ese campo de historia de las ideas económicas. Todos ellos reflejan un espíritu "comunitarista", que responde al pensamiento de una sociedad cristiana muy preocupada por el bien común, la solidaridad, etc. (cuestión que no ha perdido su actualidad, si revisamos por ejemplo la reciente Doctrina Social de la Iglesia o el magisterio del actual Papa Francisco... lo que tampoco es posible abordar en este momento).

$\underline{\text { Un peculiar modelo de organización social: ciudades de } 6.000 \text { familias }}$

Resulta llamativa la coincidencia en cuanto al número de habitantes de ambas propuestas. Tomás Moro había escrito sobre la ínsula de Utopía:

La ciudad está constituida por familias... A fin de evitar que las ciudades se despueblen o crezcan demasiado, procuran que cada familia (una ciudad comprende seis mil familias, sin contar la comarca rural) no tenga menos de diez adultos ni más de dieciséis 29.

Pues bien, leamos la propuesta de Vasco de Quiroga:

Conviene... que una ciudad de seis mil familias, y cada familia de diez hasta diez y seis casados familiares de ella, que son sobre sesenta mil vecinos, sea tan bien regida y gobernada en todo como si fuese una sola familia, así en lo espiritual como en lo temporal ${ }^{30}$.

\section{La planificación del trabajo: jornadas de 6 horas}

En este punto sobre la jornada laboral, la propuesta de Moro seguramente resultaba tan sorprendente para sus contemporáneos que tuvo que explicar con mucho detalle el empleo de las horas del día y la organización del trabajo en la isla de Utopía:

Los utopienses... dividen el día, comprendida la noche, en veinticuatro horas iguales de las que destinan solamente seis al trabajo: tres antes del mediodía,

\footnotetext{
${ }^{29}$ Tomás Moro, Utopía (Madrid: Rialp, 1989): 127.

${ }^{30}$ Vasco de Quiroga. "Información en derecho", en Quiroga, La utopía en América: 224.
} 
para almorzar a continuación; y luego de haber comido y reposado dos horas por la tarde, trabajan de nuevo otras tres horas, terminando con la cena... La mayoría consagra esos ratos de ocio a los estudios humanísticos; y es costumbre que se den a diario conferencias públicas a primera hora de la mañana...

Pero hay aquí una cuestión que requiere detenido examen, si es que no queremos llamarnos a engaño: el hecho de que dediquen solamente seis horas al trabajo, ¿no ocasionará escasez de artículos de primera necesidad? Harto improbable es que así suceda, porque ese tiempo de trabajo no sólo resulta suficiente sino que basta y sobra para producir abundantemente cuanto se precisa... ${ }^{31}$

Fijémonos ahora en la propuesta de don Vasco para los Pueblos-Hospital, recogida en sus Ordenanzas: también habla exactamente del mismo número de horas que Tomás Moro, aunque no lo justifica con tanto pormenor.

Particular distribución de lo adquirido con las seis horas en común, según lo que cada uno haya menester para sí y para su familia.

Ítem lo que así de las dichas seis horas de trabajo en común como dicho es se hubiere, después de así habido y cogido, se reparta entre vosotros todos, y cada uno de vos en particular aeque congrua ${ }^{32}$.

\section{La abolición del dinero}

Termino con otra cuestión que también expresa una utopía espiritual y colectivista (y que ha sido incluso calificada como precursora del comunismo marxista $\left.^{33}\right)$ : la restricción del uso de la moneda en la ínsula de Utopía. Así propone Tomás Moro:

No utilizan moneda, en efecto; pero la reservan para cualquier eventualidad, que bien podrá o no presentarse. Mientras tanto guardan el oro y la plata -con los que se acuña el dinero- sin estimarlos más de lo que merece su naturaleza: ¿es que no salta a la vista cuán inferiores son al hierro?34

\footnotetext{
31 Moro, Utopía: 122-123.

32 Vasco de Quiroga. “Ordenanzas”, en Quiroga, La utopía en América: 255.

${ }^{33}$ Como vengo señalando, no tenemos ocasión aquí para analizar mínimamente el sentido último que pretendía Moro con su libro. Se ha conjeturado mucho sobre un hipotético programa de ingeniería social, en esa línea que estamos llamando "comunitarista"; sin embargo, en las más recientes ediciones de la Utopía, los estudiosos tienden a considerar el texto del Canciller inglés como una invitación a la "reforma personal de uno mismo" (Moro, Utopía: 12) y ello con el lenguaje y estilo del humanista culto que fue Tomás Moro, no exento de una finísima ironía (Ibídem: 15). Nosotros, por otra parte, lo que estamos tratando de analizar ahora son las posibles relaciones entre esta obra y la sorprendente fundación -una idea llevada a la realidad- de los Pueblos-Hospital de Vasco de Quiroga.

${ }^{34}$ Moro, Utopia: 137.
} 
Remata su propuesta con una ironía en esa línea humanista que hemos señalado, ya que el oro y la plata se dedicarían principalmente a la producción de «orinales y diversos recipientes de uso ignominioso», así como «para fabricar cadenas y forjar grilletes macizos con los que aherrojar a los esclavos» ${ }^{35}$. Evidentemente, aquí hay algo que va más allá de un modelo de organización social: se trata de una ingeniosa y ácida crítica de la natural tendencia del hombre hacia la posesión de metales preciosos...

¿Y qué encontramos al respecto en don Vasco? La verdad es que habla del dinero con la naturalidad de quien sí está promoviendo una institución real como fueron los Pueblos-Hospital (y no escribiendo un ensayo): Quiroga da por sentado que claro que hay que usar monedas para el intercambio económico en la sociedad virreinal en la que vivía. Pero al mismo tiempo parece que reduciría su empleo a las operaciones exteriores de sus comunidades, mientras que el reparto interno de bienes se haría mediante el intercambio de los frutos del trabajo: ya lo hemos visto arriba cuando se habla de un reparto "equitativo" (aequo congruo) del trabajo realizado en esas seis horas diarias «según lo que cada uno, según su calidad y necesidad, manera y condición, lo haya menester para sí y para su familia». Pero un poco más adelante precisa un almacenamiento de lo sobrante, que sería mediante un «arca de tres llaves para la moneda del común», precisando «quiénes las han de tener y dónde ha de estar guardada ${ }^{36}$.

En conclusión, parece que podemos incluir perfectamente al obispo Vasco de Quiroga en la lista de los "emprendedores" de nuestra España moderna, a juzgar por su sorprendente fundación (que perduraría hasta el siglo XIX) de los Pueblos-Hospital. Otra cosa sería identificar su inspiración con la Utopía de Tomás Moro: algo que hemos visto arriba que comparten muchos investigadores... Pero su confirmación sigue todavía sujeta a un interesante debate historiográfico que excede los límites del presente trabajo. Por ejemplo, terminaré señalando otra vía de interpretación para las iniciativas de don Vasco, tal vez menos conocida pero sugerente: su adscripción al modelo humanista de Erasmo de Rotterdam, más centrado en la idea del buen ejemplo de los dirigentes que en la organización político-social de los gobernados ${ }^{37}$.

\footnotetext{
35 Ibídem: 138.

${ }^{36}$ Quiroga. “Ordenanzas”: 264.

${ }^{37}$ Ross Dealy, The Politics of an Erasmian Lawyer, Vasco de Quiroga (Malibu: Undena, 1976). La autora justifica su teoría en varias citas que hace don Vasco del Paraclesis de Erasmo (1519).
} 


\section{BIBLIOGRAFÍA}

Álvarez Vázquez, José Antonio, "Financiación de las fundaciones teresianas", en Actas del I Congreso Internacional Teresiano (Salamanca-Madrid: Universidad PontificiaMinisterio de Cultura, 1983), 249-285.

Álvarez Vázquez, José Antonio, Trabajo, dinero y negocios (Madrid: Trotta, 2000).

Arce Gargollo, Pablo, "Guía Bibliográfica”, en Vasco de Quiroga, jurista con mentalidad secular (México: Porrúa, 2007).

Cerezo, Prometeo, Alonso de Veracruzy el derecho de Gentes (México: Porrúa, 1985).

Dealy, Ross, The Politics of an Erasmian Lawyer, Vasco de Quiroga (Malibu: Undena, 1976).

Hanke, Lewis, La lucha por la justicia en la conquista de América (Madrid: Itsmo, [1949] 1988).

Hanke, Lewis, Estudios sobre fray Bartolomé de Las Casas y sobre la lucha por la justicia en la conquista española de América (Caracas: Universidad Central de Venezuela, 1968).

Martín Hernández, Francisco, Don V asco de Quiroga (protector de los indios) (Salamanca: Universidad Pontificia- Caja de Salamanca y Soria, 1993).

McLelland, David C., The Achieving Society (Princeton, NJ: D. Van Nostrand, 1961).

Moreno, Juan Joseph, Fragmentos de la Viday Virtudes del V. Ilmo. y Rmo. Sr. Dr. D. Vasco de Quiroga (México: Imprenta del Real y más antiguo Colegio de San Ildefonso, 1776).

Moro, Tomás, Utopía (Madrid: Rialp, 1989).

Quiroga, Vasco de, La utopia en América, ed. Paz Serrano Gassent (Madrid, Dastin: 2002).

Robles Diosdado, Juan, V asco de Quiroga. Laico misionero (Morelia: UVAQ, 2010).

Santos Redondo, Manuel, Los economistas y la empresa. Empresa y empresario en la historia del pensamiento económico (Madrid: Alianza Editorial, 1997).

Santos Redondo, Manuel, "Espíritu de empresa: mentalidades y teorías del empresario", en Estudios de historia del pensamiento económico: homenaje al profesor Francisco Bustelo (Madrid: Editorial Complutense, 2003), 531-540. 
Santos Redondo, Manuel, "La economía y la empresa en las novelas de Cervantes", CLM Economía 5 (2004): 161-188.

Serrano Gassent, Paz, Vasco de Quiroga. Utopía y derecho en la conquista de América (Madrid: Fondo de Cultura Económica, 2001).

Veracruz, Alonso de, De Iusto Bello contra Indos (Madrid: CSIC, 1997).

Zavala, Silvio, "La utopía de Tomás Moro en la Nueva España y otros estudios", en Biblioteca histórica mexicana de obras inéditas (México, Porrúa: 1937), vol. 4.

Zavala, Silvio, Recuerdo de V asco de Quiroga (México: Porrúa, 1965).

Zavala, Silvio, Las instituciones jurídicas en la conquista de América (México, Porrúa, 1971).

Zavala, Silvio, Filosofía de la conquista (México: Fondo de Cultura Económica, 1984).

Zavala, Silvio, Temas hispanoamericanos en su Quinto Centenario (México: Porrúa, 1986).

Recibido: 31 de marzo de 2017 Aprobado: 29 de noviembre de 2017 